\title{
Study on Modulus of Elasticity of Reinforced Clay
}

\author{
Amin Chegenizadeh ${ }^{1, a}$, Prof. Hamid Nikraz ${ }^{2, b}$ \\ ${ }^{1} \mathrm{PhD}$ candidate, Department of Civil Engineering, Curtin University of Technology, Perth, \\ Australia; Tel: +61-413165961; Fax: +61 892662681 \\ ${ }^{2}$ Prof. Hamid Nikraz, Head of the Department of Civil Engineering, Curtin University of \\ Technology, Perth, Australia; Tel: +61 89266 7573; Fax: +61 892662681 \\ a Email: amin.chegenizadeh@postgrad.curtin.edu.au, \\ b Email: H.Nikraz@curtin.edu.au
}

\begin{abstract}
Reinforced soil has been among the most effective soil modification materials. Its use has been expanded rapidly into civil engineering, geotechnical engineering and pavement engineering. Reinforcing subgarde in pavement systems has always been an issue. This study focuses on effect of fibre inclusion on the modulus of elasticity of subgrade material. Plastic fibre was used for this investigation. Fibre contents and aspect ratio have been changed during these tests. The fibre percentage varied from $0 \%$ (for unreinforced samples) to $6 \%$. Clay was used as sub grade material. Unconfined compression tests were carried out to investigate behaviour of the composite under different condition. The fibre length and fibre content found to play important rule on the modulus of elasticity of fibre. Furthermore it was observed that ductility of sample increased by fibre inclusion.
\end{abstract}

Keywords: Reinforced soil, Unconfined, Strength, Fibre.

\section{INTRODUCTION}

In conventional application of reinforcement in soil, the inclusion of tire, bars, grids etc are usually in a preferred orientation. The advances of these materials have usually been considered by an increase in their applications. The randomly discrete fibers are easily added and mixed randomly with soil part, the same way as cement, lime or other additives. Some researches have been done on cement additive (Consoli et.al. 2009; Cai et.al 2006; Lorenzo and Bergado, 2004) and can be used as a pattern of additive usage in soil. Fibre reinforced composite shows more ductility and small losses of peak strength i.e. in compared to unreinforced material. Therefore, fiber-reinforced soil composite is a practical solution in civil engineering projects. The main application of composite soil can be in embankment, subgrade, subbase, and slope stability problems. However, the data concerning the effects of fiber inclusion on the characteristics of compacted native or virgin soils are limited, (Maher and Ho, 1993). This shortage is more considerable in pavement engineering therefore research on fibre inclusion in pavement systems needs to be more performed. As in pavement engineering modulus of elasticity has considerable effect on the design procedure, this study is mainly focused on changes in this parameter due to random fibre inclusion. 


\section{MATERIAL}

Composite materials consist of two parts. The first part is soil part which can be dealt as normal soil. The second part is reinforcement part which can be made up of any material which helps soil to have better performance.

\section{Soil Type}

The soil type in this study was kaolin clay. The properties of kaolin clay are presented in table 1.

Table1. Clay properties

\begin{tabular}{ccc}
\hline No. & Type & \\
\hline 1 & Soil type & Clay \\
2 & Liquid Limit & 49 \\
3 & Plastic Limit & 23 \\
4 & Pl. Index & 26 \\
\hline
\end{tabular}

\section{Fibre Type}

The plastic fibre has been used for this investigation. The fibre properties are presented in table 2. The fibre is commercially available and is called fibre Meyco FIB SP 65 macro structural synthetic polypropylene fibre which generates a very high energy absorption rate when used in the matrix. Figure 1 shows the used fibre.

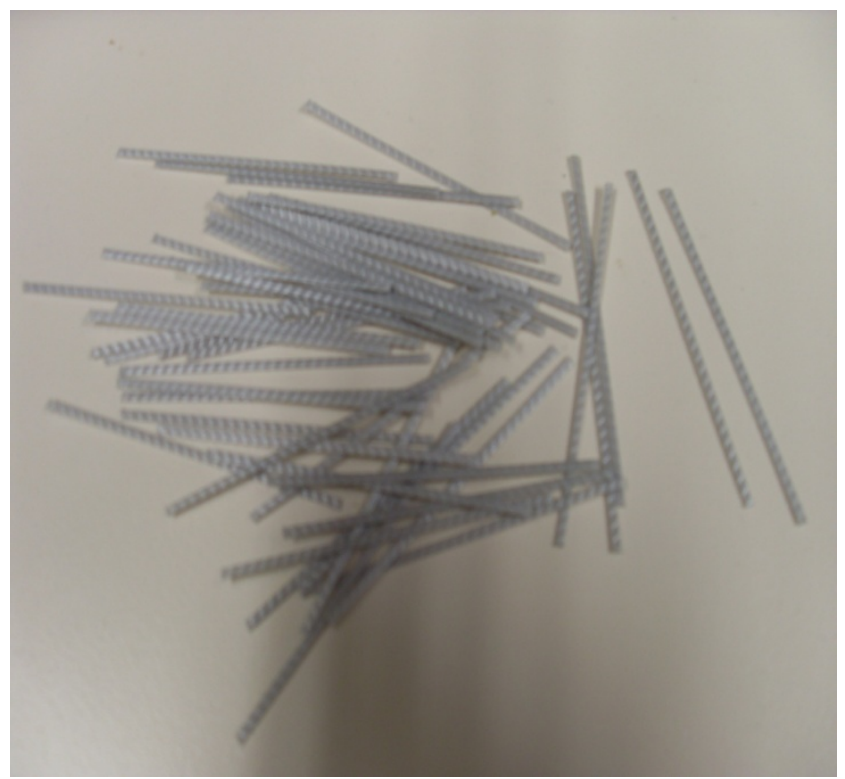

Fig. 1 Plastic fibre

Table2. fibre properties

\begin{tabular}{ccc}
\hline No. & Type & \\
\hline 1 & Material & Polypropylene \\
2 & Specific Gravity & 0.92 \\
3 & Width & $1.6825 \mathrm{~mm}$ \\
\hline
\end{tabular}




\section{TEST PROGRAM}

A series of unconfined compression tests have been conducted to verify effect of fibre content on elasticity modulus.

\section{Unconfined Compression Test Principle}

Aim of Unconfined Compression test is to obtain unconfined compressive strength of soil. This can be applied to fine grade and cohesive soil and will represent very fast response in practical condition as the test time is very quick in respect to confined one. This test is widely used for slope stability and embankment dam applications.

\section{Equipment}

- Unconfined compression testing machine (Triaxial Machine) as shown in figure 2

- $\quad$ Specimen preparation equipment

- Sample extruder

- fibre

- Balance

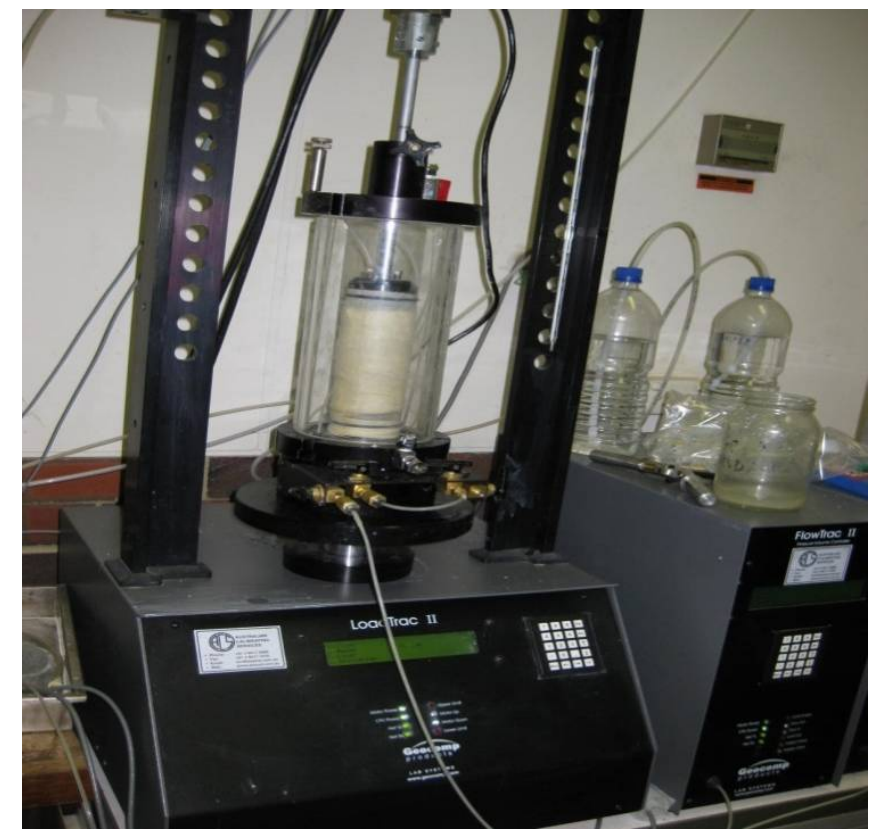

Fig. 2 Triaxial machine

\section{Sample Preparation}

The samples were prepared by mixing clay and four percentage of fibre. Specimen preparation method was the standard compaction method, which was used in an ongoing experimental research on fiber-reinforced clay at Curtin University. The soils were first ovendried. The dry soils were then crushed using a hammer. A mixer was used to thoroughly mix the soils with water to obtain the desired water moisture content for compaction. The mixing of soil with fibers was performed mostly by hand rather than using the mixer because the mixer caused the fibers to tangle or break. The fiber-soil mixture was placed in a closed container for 24 hours after mixing was completed. A split mold and a specific hammer were 
used to compact the specimen. The specimens were prepared in different fibre content (i.e. $1 \%, 3 \%, 6 \%$ ) and different fibre length (aspect ratio) which were $20 \mathrm{~mm}, 30 \mathrm{~mm}, 60 \mathrm{~mm}$.

\section{Test Procedure}

1. The specimens were prepared in the laboratory with $90 \%$ compaction effort, special care was taken during this process

2. The size of samples were checked to be suitable for the test purpose

3. The samples were put for 24 hours in geotxtile and packed

4. Special attention was applied for preventing any moisture loose

5. The samples were put in trixial base without any confinement pressure

6. According to ASTM $1.27 \mathrm{~mm} / \mathrm{min}$ were applied through the tests

7. The data was collected automatically

8. The stress-strain curve plot used for modulus elasticity investigation

\section{Results and Discussion}

The unconfined compression tests were performed in order to determine the modulus of elasticity (E-value). The E values were calculated based on the initial tangent of the stressstrain curve. The tests were conducted on cylindrical specimen of $60 \mathrm{~mm}$ diameter and 170 mm height.

Table 3 provides values of elastic modulus of soil with and without fiber reinforcement. The maximum E-value of clayey soil was $15010 \mathrm{kPa}$ obtained at the aspect ratio of $60 \mathrm{~mm}$ and fiber content $6 \%$ percent. It was observed that modulus of elasticity was increased with increasing in fibre length and fibre content.

Table 3 E-Values (kPa) for Reinforced and Unreinforced Soils

\begin{tabular}{ccc}
\hline Fibre length(mm) & Fiber content \% & E value \\
\hline----- & 0.00 & 5500 \\
20 & 1 & 9010 \\
& 3 & 11000 \\
& 6 & 12363 \\
30 & 1 & 11000 \\
& 3 & 12200 \\
& 6 & 12650 \\
& & 14000 \\
& & 14605 \\
& 1 & 15010 \\
\hline
\end{tabular}




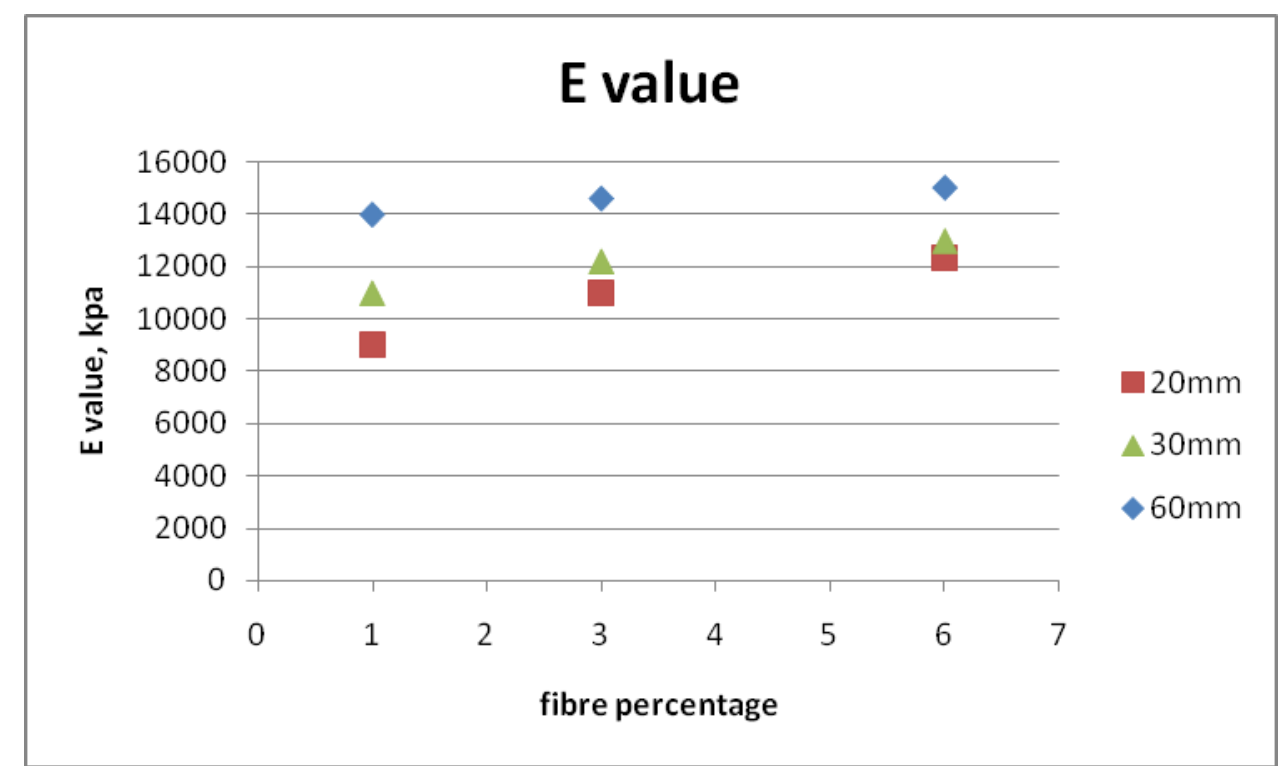

Fig. 3 Effect of fibre percentage and length on modulus of elasticity

\section{CONCLUSION}

A series of Unconfined Compression tests were performed and conclusions can be summarized as:

- Increasing in fibre percentage increased modulus of elasticity

- Increasing in fibre aspect ratio increased modulus of elasticity

- During the test, it was observed that ductility behavior of reinforced clay increased because of fibre inclusion.

- Short and randomly fibre inclusion showed to be reliable solution to enhance strength of the composites.

\section{ACKNOWLEDGEMENTS}

Authors would like to thank Curtin laboratory staff for their kind assistance.

\section{REFERENCES}

[1]Akbulut, S., Arasan, S. and Kalkan, E. (2007) Modification of clayey soils using scrap tire rubber and synthetic fibres, Journal of Applied Clay Science 38, 23-32.

[2]Al Refeai, T.O. (1991) Behaviour of granular soils reinforced with discrete randomly oriented inclusions, Journal of Geotextiles and Geomembranes 10, pp. 319-333.

[3]Cai, Y., Shi, B., Charles, W.W. Ng. \& Tang, C. (2006) Effect of polypropylene fibre and lime admixture on engineering properties of clayey soil, Engineering Geology 87, $230-240$.

[4]Consoli, N.C., Vendruscolo, M.A., Fonini, A. and Dalla Rosa, F. (2009) Fibre reinforcement effects on sand considering a wide cementation range, Geotextiles and Geomembranes 27, pp. 196-203.

[5]Freitag, D.R. (1986) Soil randomly reinforced with fibres, Journal of Geotechnical Engineering ASCE 112 (8), pp. 823-826. 
[6]Lorenzo, G. A. and Bergado, D. T. (2004). Fundamental parameters of cementadmixed clay - New approach. Journal of Geotechnical and Geoenvironmental Engineering, Vol. 130, No. 10, pp. 1-9.

[7]Michalowski, R. L., Cermak, J. (2002), Strength anisotropy of fiber-reinforced sand. Computers and Geotechnics, Vol. 29, No. 4, pp. 279-299.

[8]Maher, M. H., Ho, Y. C. (1994), Mechanical-properties of kaolinite fiber soil composite. J. of Geotech. Engrg, ASCE, Vol. 120, No. 8, pp. 1381-1393.

[9]Nataraj, M. S., Mcmanis, K. L. (1997), Strength and deformation properties of soils reinforced with fibrillated fibers. Geosynthetics Int., Vol. 4, No. 1, pp. 65-79.

[10] Sivakumar Babu, G.L., Vasudevan, A.K. and Haldar, S. (2008) Numerical simulation of fibre-reinforced sand behaviour, Geotexiles and Geomembranes 26, pp. 181-188.

[11] Yetimoglu, T. and Salbas, O. (2003) A study on shear strength of sands reinforced with randomly distributed discrete fibres, Geotextiles and Geomembranes 21 (2), pp. 103-110.

[12] Ziegler, S., Leshchinsky, D., Ling, H. I., and Perry, E. B. (1998) Effect of short polymeric fibers on crack development in clays. Soils and Foundations, Vol. 38, No. 1, pp. 247-253.

[13] Zornberg, J. G., Cabral, A. R. and Viratjandr, C. (2004) Behavior of tire shredsand mixtures, Canadian Geotechnical Journal 41 (2), pp. 227-241.

[14] Zornberg, J. G. (2002) discrete framework for limit equilibrium analysis of fibre-reinforcement, Geotechnique Journal 52 (8), pp. 227-241. 